\title{
FLORA DA SERRA DO CIPÓ, MINAS GERAIS: RUTACEAE (1)
}

\author{
JOSÉ RUBENS PIRANI
}

Instituto de Biociências, Universidade de São Paulo, CP 11461 - 05499 - São Paulo, SP.

\begin{abstract}
Flora of the Serra do Cipo, Minas Gerais: Rutaceae). The study of the family Rutaceae is a part of the project of "Flora of Serra do Cipó, Minas Gerais, Brasil". In that area, the family is represented by the following species: Esenbeckia febrifuga (St. Hil.) Adr. Juss. ex Mart., E. grandiflora Mart. subsp. grandiflora, Galipea multiflora Schultes, Zanthoxylum rhoifolium Lam. and Dictyoloma vandellianum Adr. Juss. Keys to the genera and species, descriptions and illustrations, as well as comments on the geographic distribution, habitats, phenology and variability of the species are presented.
\end{abstract}

RESUMO - (Flora da Serra do Cipo, Minas Gerais: Rutaceae). O estudo da família Rutaceae é parte do levantamento da Flora da Serra do Cipo, Minas Gerais, Brasil. Esta família está representada naquela área, pelas espécies: Esenbeckia febrifuga (St. Hil.) Adr. Juss. ex Mart., E. grandiflora Mart. subsp. grandiflora, Galipea multiflora Schultes, Zanthoxylum rhoifolium Lam. e Dictyoloma vandellianum Adr. Juss. São apresentadas chaves para gêneros e espécies, descriçōes e ilustraçōes das mesmas, além de comentários sobre sua distribuição geográfica, fenologia e variabilidade.

Key words: Rutaceae, Serra do Cipó floristics.

\section{RUTACEAE}

Árvores, arbustos ou ervas; caule, folhas, flores e frutos geralmente com glândulas contendo óleos voláteis aromáticos. Folhas alternas, raramente opostas, simples, pinadas ou digitadas, com pontuações translúcidas. Inflorescências variadas, geralmente cimosas, terminais ou axilares, raramente flores solitárias. Flores geralmente 3-5-meras, monóclinas e/ou díclinas (em plantas monóicas, dióicas ou poligâmicas), actinomorfas; pétalas livres, raramente unidas ou ausentes; androceu isostêmone, diplostêmone ou polistêmone; filetes livres, raramente unidos; estaminódios presentes nas flores funcionalmente pistiladas; disco intra-estaminal quase sempre presente; carpelos (1-) 2-5 (-muitos), livres ou parcial a totalmente concrescidos, reduzidos ou ausentes nas flores funcionalmente estaminadas; $\delta$ vulos 1-2 por lóculo, raramente mais, anátropos, colaterais ou superpostos, geralmente axilares. Frutos variados: folículo, drupa, cápsula, baga, samaroídeo, esquizocárpico ou hesperídio; sementes 1-2 (-muitas) por lóculo, endosperma carnoso ou ausente.

Bibliografia básica - Cowan \& Smith (1973), Engler (1874, 1931), Kaastra (1982).

\section{Chave para os gêneros}

1. Folhas bipinadas; filetes providos de apêndice basal bffido e piloso; sementes aladas ........................... . . Dictyoloma

1'. Folhas simplesmente pinadas ou simples ou trifolioladas; filetes desprovidos de apêndice; sementes globosas a oblongas, exaladas.

2. Folhas pinadas; flores diclinas; frutos geralmente unicocas, com 1 semente .............................. 3anthoxylum

2'. Folhas simples ou trifolioladas; flores monóclinas; fruto cápsula composta de 4-5 carpidios parcialmente unidos.

(1) Trabalho feito dentro do planejamento apresentado por Giulietti et al. (1987). Parte da Dissertação de Mestrado apresentada ao Depto. de Botânica do Instituto de Biociências, USP, sob orientaçáo de A.M.Giulietti. 
3. Follolos com ápice emarginado; corola gamopétala, tubulosa, estreita, levemente zigomorfa, com 2 estames e 3-6 estaminódios adnados ao tubo; cápsula rugulosa, sem formações espiniformes ......................... Galipea

3'. Folhas ou foliolos de ápice não emarginado; corola dialipétala, actinomorfa; estames 5, livres da corola, estaminódios ausentes; cápsula densamente coberta de

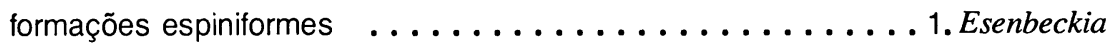

\section{Esenbeckia Kunth}

Arbustos ou árvores. Folhas alternas ou opostas, simples ou 1-5-folioladas, com pontuações translúcidas. Inflorescências paniculadas, terminais ou axilares, bracteadas. Flores monóclinas, geralmente 5-meras, actinomorfas; pedicelo geralmente com 2 bractéolas à meia-altura; pétalas livres, membranáceas ou carnosas; estames 5, alternos com as pétalas; ovário deprimido, circundado pelo disco anular, 5-carpelar, superfície freqüentemente irregular a espinhosa; óvulos (1-)2 por lóculo, colaterais. Cápsulas lenhosas fendendo-se septicida e loculicidamente em 4-5 carpldios bivalvares, geralmente com a superfície externa coberta de tubérculos espessos; endocarpo claro e elástico.

\section{Chave para as espécies}

1. Folhas simples, alternas a subopostas; inflorescência pauciflora curta (geralmente até $6,0 \mathrm{~cm}) \quad \ldots \ldots \ldots \ldots \ldots \ldots \ldots \ldots \ldots \ldots \ldots \ldots \ldots \ldots \ldots \ldots \ldots$ grandiflora 1'. Folhas trifolioladas, opostas; inflorescência multiflora longa e laxa (mais de $10,0 \mathrm{~cm}$ ) .............................. 2. E. febrifuga

1. Esenbeckia grandiflora Mart. Nova Gen. Sp. PI. 3: 85. 1831.

Figs. 1-6

Nomes vulgares: guaxupita, pau-de-cotia.

Arbustos ou arvoretas 2,0-5,0 m alt. Folhas simples, alternas a subopostas, subcoriáceas, elipticas a obovadas a oblanceoladas, ápice obtuso ou raramente acuminado, base cuneada, glabras ou com pêlos esparsos na nervura média, 4,5-14,0 cm compr., 2,0-6,0 cm larg.; peciolo rugoso espessado (geniculado) no ápice. Inflorescências paucifloras, 3,0-6,0 cm compr. Cápsula lenhosa, subglobosa, ca. 2,5 cm compr., externamente coberta de tubérculos espiniformes piramidais, retos ou levemente recurvados; endocarpo amarelado; sementes 1 por carpídio, lisas, escuras.

Figs. 1-6 - Esenbeckia grandiflora Mart. subsp. grandiflora. 1 - Ramo frutffero, 2 - Botão, 3 - Flor na antese, removida uma pétala, 4 - Flor em corte longitudinal, 5 - Ovário em corte transversal, 6 - Fruto imaturo em corte transversal (Obs. Figs. 2-5 baseadas em material florffero de São Paulo, F. C. Hoehne s.n. SP.).

Figs. 1-6 - Esenbeckia grandiflora Mart. subsp. grandiflora. 1 - Fertile shoot with fruits, 2 - Floral bud, 3 - Flower at anthesis, without one petal, 4 - Flower, longitudinal section, 5 - Ovary, transversal section, 6 - Young fruit, transversal section (Obs. Figs. 2-5 based on specimen from Säo Paulo, F.C. Hoehne s.n., $S P)$. 


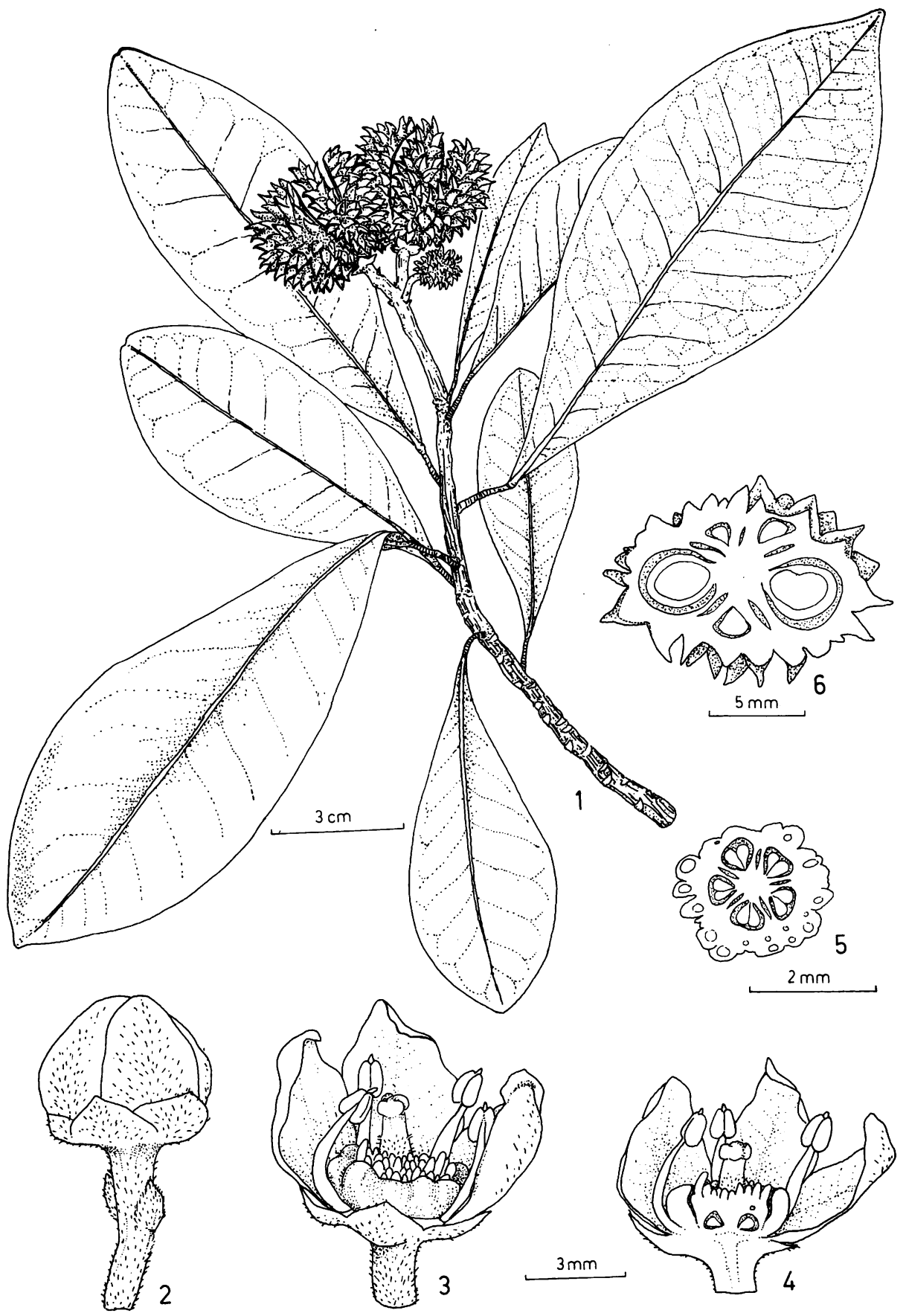


Material examinado: Santana do Riacho, Serra do Cipó, Rodovia Belo Horizonte-Conceição do Mato Dentro: km 105, Córrego Chapéu do Sol, CFSC 6668, col. J. R. Pirani, 14.X.1980, fr. (SP, SPF); km 120, Ribeirão Indequicé, CFSC 6721, col. A. Furlan, I. Cordeiro \& J.R. Pirani, 8.XI.1980, fr. (SP,SPF); CFSC 7157, col. I. Cordeiro, J.R. Pirani \& M.C. Amaral, 3.III.1981, fr., (SP, SPF).

Espécie distribuída pelo Paraguai e norte da Argentina, sul, sudeste e nordeste do Brasil, sendo, segundo Kaastra (1982), muito rara na Amazônia mas alcançando o Suriname e Venezuela. No Brasil, habita a floresta pluvial e também matas de restinga e florestas do interior.

Na Serra do Cipó, onde está representada por Esenbeckia grandiflora subsp. grandiflora var. grandiflora (conforme o tratamento de Kaastra 1982), é pouco freqüente, aparecendo como arbusto ou arvoreta do interior das matas mais secas.

2. Esenbeckia febrifuga (St. Hil.) Adr. Juss. ex Mart. Nov. Gen. Sp. PI. 3: 82, t. 233. 1831.

Nomes vulgares: grumarim (cf. Glaziou); mendanha, três-folhas.

Arbustos ou árvores 4,0m alt. Folhas trifolioladas, opostas, cartáceas; pecíolo 2,0-6,0 cm compr., liso, canaliculado superiormente; foliolos peciolulados, elípticos a oblongo-elipticos, ápice atenuado a obtuso ou acuminado, base atenuada, glabros, o mediano maior que os laterais, $3,0-13,0 \mathrm{~cm}$ compr., $1,5-4,5 \mathrm{~cm}$ larg. Paniculas terminais multifloras, $14,0-23,0$ cm compr., pubescentes. Flores monóclinas, 5-meras, alvas; pedicelo com 2 bractéolas agudas à meia-altura, piloso; sépalas oval-obtusas, ciliadas; pétalas elípticas, membranáceas, glandulfferas, na face externa esparsamente pubérulas; disco urceolado, 10-lobado; ovário 5-carpelar, 5-locular, circundado pelo disco, coberto de papilas alongadas, estilete cilindrico glabro, estigma capitado.

Material examinado: Conceição do Mato Dentro, Serra do Cipó, Estrada do Pilar, km 151, M. Barreto 8960, 3.Il.1938, fl. (BHMH,R); Fazenda do Cipó, Glaziou 18973, 26.IV.1892, fl. (R).

Espécie distribuída principalmente pelo sudeste e sul do Brasil (de Minas Gerais ao Paraná), Paraguai e Argentina, ocorrendo em florestas e capoeirões (Kaastra 1982). Na região da Serra do Cipó parece ser rara, tendo sido coletada apenas duas vezes.

\section{Galipea Aubl.}

Galipea multiflora Schultes Mantissa 1, Add. 1, p. 194. 1822.

Nomes vulgares: três-folhas, guamixinga, angustura, guaruba.

Arbustos ou arvoretas 3,0-7,0 m alt. Folhas trifolioladas, alternas, cartáceas, glabras; peciolo 3,0-6,0 cm compr., complanado adaxialmente; folílos lanceolados a elíptico-lanceolados, ápice acuminado com o acúmen emarginado, base cuneada, o mediano simétrico e maior que os laterais, que são ligeiramente assimétricos, $5,0-18,0 \mathrm{~cm}$ compr., $2,0-5,5 \mathrm{~cm}$ larg. Paniculas terminais ou subterminais, multifloras, as ramificações laterais cimosas, 8,0 - 
25,0 (-29,0) cm compr., glabras. Flores 5-meras, creme-esbranquiçadas, monóclinas; cálice cupuliforme, ca. 2,0 mm compr., 5-denteado, pubérulo externamente; corola gamopétala estreitamente tubulosa, ca. 1,6 cm compr., com 5 lobos obtusos patentes de ca. 5,0-8,0 mm compr., ligeiramente zigomorfa, glandulífera, externamente pubérula, internamente vilosa; estames férteis 2, estaminódios 3-6, todos adnados ao tubo corolino, pilosos, o conectivo das anteras apendiculado na base; ovário globoso-deprimido, glabro, 5-carpelar, 5-locular, circundado pelo disco urceolado; óvulos 2 por lóculo, superpostos; estilete anguloso, alongado, exserto; estigma capitado. Cápsula lenhosa, rugulosa, ca. 1,0 cm compr., fendendose em 5 carpídios loculicidas coerentes na base e no ápice; semente 1 por carpídio, lisa, castanho-escura.

Material examinado: Serra do Cipó, base da serra, A.P. Duarte 11387, 11.Il.1969, fl. fr. (BHMH, HEH).

Espécie freqüentemente referida na literatura botânica como Galipea jasminiflora (St. Hil.) Engler, binômio que deve ser tomado como sinônimo, por prioridade, de G. multiflora Schultes, conforme foi proposto por Albuquerque (1985).

Trata-se de espécie comum no interior de florestas mesófilas ou pluviais do Brasil central e sudeste, com distribuição conhecida em Goiás, Minas Gerais, Rio de Janeiro e São Paulo. Na Serra do Cipó é rara, tendo sido coletada uma única vez na base da serra, onde segundo referência do coletor aparecia no "subbosque de capão remanescente".

\section{Zanthoxylum L.}

Zanthoxylum rhoifolium Lam. Enc. Met. Bot 2(2): 39. 1786.

Figs. 7-17

Nomes vulgares: mamica-de porca, maminha-de-cadela.

Árvores ou arvoretas 4,0-8,0 m alt., tronco geralmente provido de acúleos bem alarjados. Folhas alternas, pari- ou imparipinadas, 6,0-20,0 cm compr., densa a esparsamente cobertas de pêlos estrelados, freqüentemente com acúleos no raque ou nas nervuras dos foliolos; raque estreitamente alada; foliolos 10-20, opostos a subopostos, membranáceos, subsésseis, elípticos a oblongo-elipticos, 1,8-5,2 cm compr., 0,7-2,0 cm larg., ápice obtuso a agudo, margem serrado-crenada, com glândulas entre os lobos marginais e espalhadas pela lâmina, base oblíqua, diminutamente estrelado-pubérulos em ambas as faces. Panículas terminais multifloras, 4,0-12,0 cm compr., estrelado-pilosas. Flores díclinas, 5-meras, 2,3-4,0 $\mathrm{mm}$ compr., alvo-esverdeadas, pediceladas; pétalas livres, oblongo-elípticas, glabras. Flores estaminadas: estames 5, ca. 3,0 mm compr.; disco anular glabro, pistilódio cônico. Flores pistiladas: estaminódios 5, triangulares, ca. 0,3 mm compr.; disco anular glabro; ovário 1(-23)-carpelar, glabro, subgloboso; óvulos 2 por lóculo, subapicais, colaterais; estigma subséssil, lobado ou não. Frutos geralmente unicocas, subglobosos, 3,0-5,0 mm alt., avermelhados a castanhos quando maduros, com numerosas glândulas oleiferas salientes do pericarpo; semente 1 por coca, obovóide, testa coriácea negro-luzidia, pendente pelo funículo na deiscência do fruto. 
Material examinado: Santana do Riacho, Serra do Cipo, Rodovia Belo Horizonte-Conceição do Mato Dentro: km 106, CFSC 6809, col. J.R. Pirani, I. Cordeiro \& A. Furlan, 14.XII.1980, fr. (SP, SPF); km 105, CFSC 7009, col. L. Rossi, I. Cordeiro, A. Furlan \& J.R. Pirani, 12.I.1981, fr. (SP, SPF); CFSC 7045, col. I. Cordeiro S. Mayo, J.R. Pirani, M.C. Amaral \& M. Gregory, 28.Il.1981, fr. (SP, SPF); CFSC 7702, col. J.R. Pirani \& I. Cordeiro, 3.XI.1981, fl. (SP, SPF).

Espécie de distribuição muito ampla, sendo encontrada em todo o Brasil e ainda noutros países sul-americanos (Engler 1874, Cowan \& Smith 1973). As árvores desta espécie vegetam em ambientes diversos, desde terrenos de várzea até montanhosos, em regiões de clima equatorial, tropical e até temperado. Tipicamente heliófita, Z. rhoifolium é rara no interior de matas primárias, onde só é encontrada em clareiras; aparece freqüentemente em formações secundárias, notadamente capoeirões, matas semi-devastadas ou à beira de estradas que atravessam matas. Nas matas de Minas Gerais é elemento freqüente (Heringer 1947), e em muitas áreas da Cadeia do Espinhaço, inclusive a Serra do Cipó, tem ocorrência expressiva nas bordas de matas e capoeiras.

Embora seja facilmente reconhecivel na natureza, Z. rhoifolium é a espécie mais polimórfica do gênero, com formas mais ou menos distintas, o que levou autores diversos a descreverem taxa diferentes aos niveis específico e infra-específico. Engler (1874), por exemplo, reconhece 5 variedades com base em caracteres vegetativos, apesar de admitir a existência de muitas formas intermediárias entre tais variedades. Tal tratamento tem recebido crítica de autores como Macbride (1949) e Escalante (1961). Este último acredita que todos os taxa infra-específicos descritos para $Z$. rhoifolium constituem partes de um gradiente de variações contínuas de uma espécie extremamente plástica, e que talvez até mesmo entidades descritas como espécies distintas por Engler (1874) sejam componentes de um só complexo mono-específico. O estudo das populações da Serra do Cipó e adjacências fornece evidências concordantes com esta idéia, por is 60 não são reconhecidas aqui variedades em Z. rhoifolium.

\section{Dictyoloma Adr. Juss.}

Dictyoloma vandellianum Adr. Juss. Mém. Mus. Hist. Nat. Paris 12: 499, fig. 24. 1825.

Figs. 18-33

Nomes vulgares: pau-vidro, brauninha, sabugueiro-da-mata.

Figs. 7-17 - Zanthoxylum rhoifolium Lam. 7 - Ramo com inflorescência estaminada, 8 - Pêlo estrelado, 9 - Flor estaminada, 10 - Flor estaminada, removida uma pétala e um estame, para expor o pistilodio sobre o disco, 11 - Flor pistilada, 12 - Flor pistilada sem as pétalas, expondo o gineceu sobre o di.:co com os estaminódios, 13 - Ovário em corte transversal, 14 - Gineceu em corte longitudinal, 15 - Fruto em corte longitudinal, 16 - Fruto na deiscência, com a semente pêndula para fora, 17 - Semente.

Figs. 7-17 - Zanthoxylum rhoifolium Lam. 7 - Shoot with staminate inflorescence, 8 - Stellate hair, 9 - Staminate flower, 10 - Staminate flower without one petal and one stamen, showing the pistillode on disc, 11 - Pistillate flower, 12 - Pistillate flower without the petals, showing the gynoecium on disc, with the staminodes, 13 - Ovary, transversal section, 14 - Gynoecium, longitudinal section, 15 - Fruit, longitudinal section, 16 - Fruit at dehiscence, with the pendulous seed, 17 - Seed. 

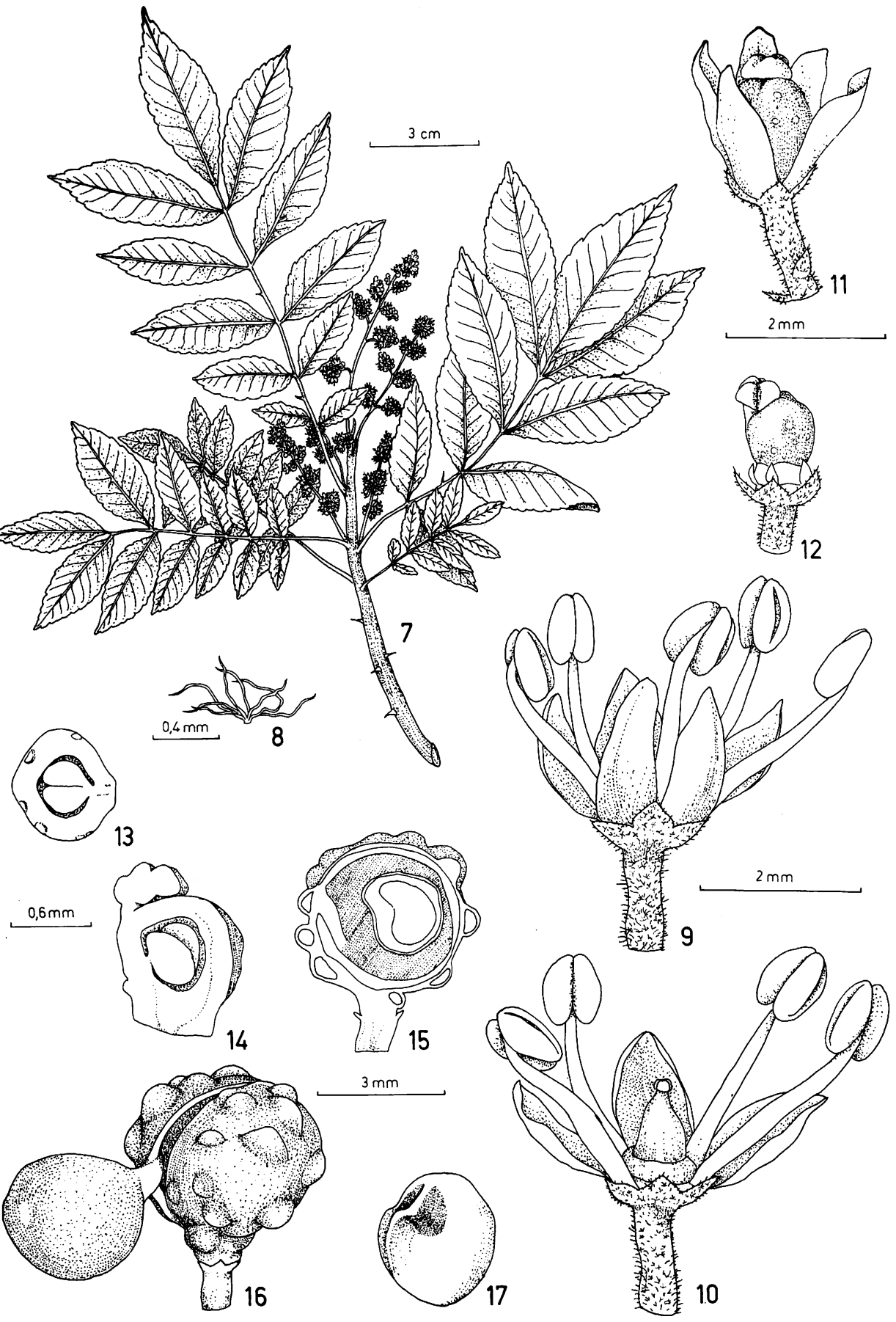


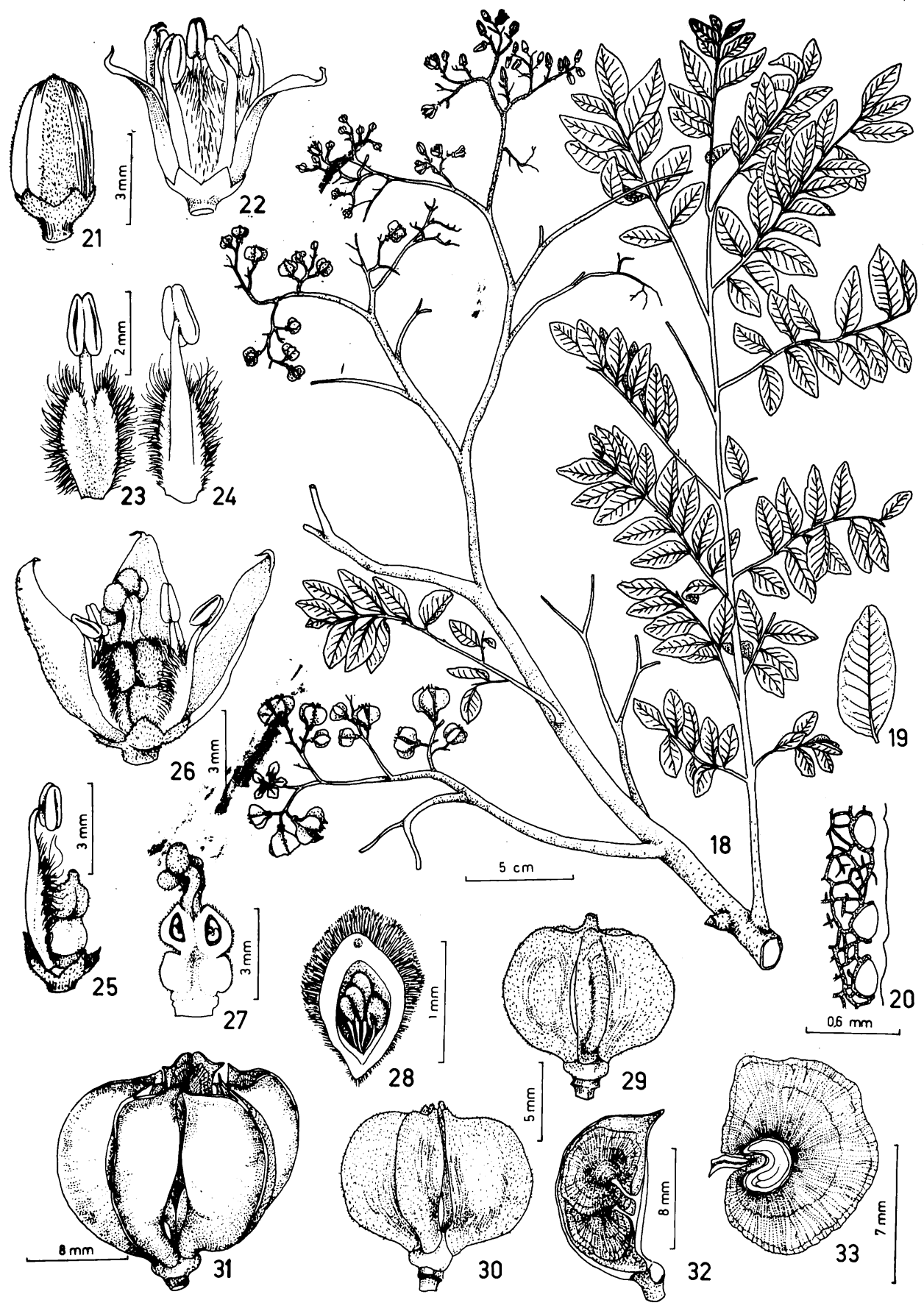


Arvoretas ou árvores 2,0-7,0 m alt. Folhas alternas, bipinadas, concentradas nas extremidades dos ramos, (8,0-) 20,0-40,0 cm compr., tomentosas; raque de $1^{\text {a }}$ ordem lenhoso, raque de $2^{\mathrm{a}}$ ordem estreitamente alado; foliólulos 5-12 pares por folíolo, discolores, 3,0-4,5 cm compr., 1,0-1,8 cm larg., oblongos, ápice obtuso a agudo, margem revoluta com glândulas, base assimétrica. Panículas amplas, 30,0-66,0 cm compr., subterminais e terminais, ferrugineo-tomentosas, multiramosas (ramificação aproximadamente dicotômica), últimos ramos corimbosos e densos. Flores numerosas, 5-meras, ca. 8,0 mm compr., creme-esbranquiçadas, perfumadas; pétalas livres, oblongas, seríceo-pilosas na região mediana externa, com apículo inflexo; estames 5 , livres, menores nas flores funcionalmente pistiladas; filetes dotados na base interna de apêndice bífido com margem densamente vilosa; gineceu 5-carpelar, 5-locular, muito reduzido nas flores funcionalmente estaminadas, assentado sobre disco espessado piloso; carpelos unidos apenas pelos estiletes, seríceo-vilosos; estigma espessado, 5-lobado; óvulos 4-5 por lóculo. Cápsula com 5 carpídios livres, semi-orbiculares, comprimidos lateralmente, atenuados na base, estipitados, pilosos, introrsamente deiscentes em 2 valvas; sementes 3-4 por carpídio, suborbicular-reniformes, muito comprimidas, com ala larga membranácea e reticulada; embrião arqueado.

Material examinado: Santana do Riacho, Serra do Cipó, Rodovia Belo Horizonte-Conceição do Mato Dentro: Estrada da Usina, CFSC 4129, col. I. Sazima, 29.IV.1973, fl. (SP, UEC); CFSC 6134, col. A. Furlan, I. Cordeiro \& J.R. Pirani, 25.V.1980, fl. fr. (SP, SPF). Santana do Pirapama, Serra Mineira (Serra do Cipó), CFSC 8448, col. J.R. Pirani, 24.III.1982, fl. (SP, SPF). Santa Luzia, L. O. Willians \& V. Assis 6742, 22.IV.1945, fl. (R, RB, $\mathrm{SP})$.

Desde 1912, Briquet já cita Dictyoloma Adr. Juss. como nomem conservandum (sobre Benjamina Vell.), indicando como espécie-tipo D. vandellianum Adr. Juss., como aparece no Código Internacional de Nomenclatura Botânica (Stafleu 1978). Contudo, certamente por causa do tratamento de Engler (1874) na Flora Brasiliensis, Dictyoloma incanescens DC. é o nome com que tem sido comumente designada esta espécie entre os botânicos brasileiros, aparecendo nos exemplares de herbário e em trabalhos florísticos, podendo-se citar Rizzini (1979), Magalhães (1956), Albuquerque (1968), Lisboa (1971), Ferreira et al. (1978). Porém, segundo o que consta na literatura citada anteriormente, conclui-se que os autores brasileiros têm empregado um nome que deve, pelas regras internacionais de nomenclatura, ser tomado como sinônimo, procedimento adotado no presente trabalho.

Figs. 18-33 - Dictyoloma vandellianum Adr. Juss. 18 - Ramo com parte da inflorescência, na qual já existem frutos, 19 - Foliólulo, 20 - Detalhe da margem do limbo, mostrando as glåndulas marginais e sua relação com o sistema vascular, 21 - Botão, 22 - Flor estaminada, 23 - Estame, vista ventral, 24 - Estame, vista dorsal, 25 - Flor estaminada sem a corola e sem 4 estames, expondo o disco com o pistilódio; 26 - Flor funcionalmente pistilada, removida uma pétala, 27 - Gineceu e disco em corte longitudinal, 28 - Um carpelo em corte transversal, 29 e 30 - Cápsula em duas fases sucessivas de maturação, 31 - Cápsula madura, com os carpídios abertos, 32 - Carpídio sem uma das valvas, expondo 2 sementes, 33 - Semente, a parte central cortada longitudinalmente.

Figs. 18-33 - Dictyoloma vandellianum Adr.Juss. 18 - Shoot with part of inflorescence, already with fruits, 19 - Leaflet, 20 - Margin of leaflet, showing marginal glands and their relation to the veinlets, 21 - Floral bud, 22 - Staminate flower, 23 - Stamen, ventral view, 24 - Stamen, dorsal view, 25 - Staminate flower, without petals and 4 stamens, showing disc and pistillode, 26 - Pistillate flower, without one petal, 27 - Gynoecium and disc, longitudinal section, 28 - Carpel, transversal section, 20-30 - Capsule, two successive stages, 31 - Capsule with fruitlets opened, 32 - Fruitlet without one of the valves, showing two seeds, 33 - Seed, with the central part in longitudinal section. 
A distribuição de $D$. vandellianum restringe-se aos estados de Minas Gerais, Bahia, Espírito Santo, Rio de Janeiro e São Paulo, não tendo sido ainda assinalada ocorrência a ceste do Rio São Francisco. O ponto setentrional extremo de registro da espécie é Jacobina (Bahia), aproximadamente a $11^{\circ} \mathrm{S}$; ao sul, os limites estão na região leste e litoral norte de São Paulo.

Na Serra do Cipó e outras áreas ao longo da Cadeia do Espinhaço, D. vandellianum habita principalmente orlas de matas e formaçōes secundárias, como capoeiras, margens de matas e estradas, formando freqüentemente populações densas. É uma espécie monóica com flores funcionalmente díclinas numa mesma inflorescência. As flores funcionalmente estaminadas têm estames exsertos com anteras repletas de pólen viável (segundo teste de coloração pelo carmim-acético, cf. Marks, 1954) e um pistilódio que pode exibir graus de redução variáveis, sendo depresso-globoso com estilete muito curto (fig. 25) nas populações da Serra do Cipó, ou muito reduzido, apresentando os carpelos torcidos em espiral e estilete relativamente alongado, conforme foi observado em espécimes de São Paulo e outras áreas de Minas Gerais. As flores funcionalmente pistiladas exibem ovário bem desenvolvido e estaminódios semelhantes aos estames normais mas menores e cujas anteras produzem pequena quantidade de pólen que é inviável (segundo teste de coloração pelo carmin-acético, cf. Marks, 1954).

O padrão de floração, bastante interessante, mostra duas fases de abertura de flores estaminadas intercaladas temporalmente por uma fase de flores pistiladas. Sendo esses periodos sincrônicos a nível de indivíduo, mas assincrónicos a nivel populacional, pode-se supor que isso torne a espécie xenógama obrigatória, embora monóica. Um padrão de floração análogo já foi descrito para espécies de Cupania e Sapindus (Sapindaceae) por Bawa (1977), que acredita que muitas espécies monóicas tropicais tenham tipo semelhante de floração.

\section{REFERENCIAS}

ALBUQUERQUE, B. W. P. 1968. Rutaceae do Estado da Guanabara. An.Acad. Bras. Ciên. 40: 499-530.

ALBUQUERQUE, B. W. P. 1985. Rutaceae. In J.A. Rizzo (ed.) Flora do Estado de Goid́s - Coleção Rizzo. vol. 6. Editora da Universidade Federal de Goiás. Goiânia.

BAWA, K. S. 1977. The reproductive biology of Cupania guatemalensis Radlk. (Sapindaceae). Evolution 31:52-63.

BRIQUET, J. 1912. Règles internationales de la nomenclature botanique. Verlag van Gustav Fischer. Viena.

COWAN, R. S. \& SMITH, L. B. 1973. Rutáceas. In R. Reitz (ed.) Flora Ilustrada Catarinense. Herbário Barbosa Rodrigues. Itajar, SC.

ENGLER, A. 1874. Rutaceae. In C.F.P. Martius (ed.) Flora Brasiliensis 12(2): 76-196.

ENGLER, A. 1931. Rutaceae. In A. Engler \& K. Prantl (ed.) Die natürlichen Pflanzenfamilien ed. 2, 19a: 187-359.

ESCALANTE, M. G. 1961. El género Fagara en la Argentinà. Boln Soc. Argent. Bot. 9: 291-317.

FERREIRA, M.B., D’ASSUMPÇÃO, W.R.C. \& MAGALHÃES, G.M. 1978. Nova contribuição para o conhecimento da vegetaçāo da Cadeia do Espinhaço ou Serra Geral (Maciço do Caraça). Oréades 6: 49-67.

GIULIETTI, A. M., MENEZES, N. L., PIRANI, J. R., MEGURO, M.\& WANDERLEY, M. G. L. 1987. Flora da Serra do Cipó, Minas Gerais: caracterização e lista das espécies. Bolm Botânica, Univ. S. Paulo 9: 1-151.

HERINGER, E.P. 1947. Contribuição ao conhecimento da flora da zona da mata de Minas Gerais. Serv. Nac. Pesq. Amazon. Min. Agr. Rio de Jan. Bol. 2.

KAASTRA, R. C. 1982. Pilocarpinae (Rutaceae). Flora Neotropica 33: 1-198.

LISBOA, M. A. 1971. A flora de Ouro Preto. Rev. Escola Minas 29: 1-10.

MACBRIDE, J. F. 1949. Flora of Peru-Rutaceae. Field Mus. Nat. Hist. (Publ.) Bot., ser. 13, 3: 655-689.

MAGALHÄES, G.M. 1956. Características de alguns tipos florísticos de Minas Gerais II. Rev. Biol. 1: 76-92. 
MARKS, G. E. 1954. An aceto-carmine glycerol jelly for use in pollen-fertility counts. Stain Technol. 29: 277.

RIZZINI, C. T. 1979. Tratado de Fitogeografia do Brasil. vol. 2. Ed. Edgard Blücher Ltda., EDUSP. São Paulo.

STAFLEU, F. A. 1978. International code of botanical nomenclature. Bohn, Scheltema \& Holkema. Utrecht. 